\title{
The Art Form and Development of the Quanzhou Lamp in the Background of the Sea Silk Culture
}

\author{
$\mathrm{Na} \mathrm{Yu}$ \\ Quanzhou Normal University, Quanzhou 362000, China \\ 497544937@qq.com
}

Keywords: Lamp; Sea Silk Culture; Art Form; Quanzhou.

\begin{abstract}
Quanzhou lamp is an important intangible cultural heritage, and it has rich cultural and artistic value in the aspects of modeling, craft and meaning. Quanzhou lamp is the material carrier of traditional culture, but in the modern society, the protection and development of Quanzhou lamp art encounters economic development, technology updating and cultural change. Under the background of the sea silk culture, the protection and development of Quanzhou lamp art should be strengthened, so as to create the fine culture of Quanzhou lamp continuously.
\end{abstract}

\section{The Historical Origin of the Quanzhou Lamp}

Quanzhou is the cultural capital of east Asia and also is the starting point of the maritime silk road, located in the southeast of Fujian province. As maritime traffic developed, it became one of China's four big foreign trade ports since the tang dynasty. It is famous for Oriental first port with more than 100 countries and regions' commercial relations including economic and cultural exchanges during the song and yuan period, as a world-class port.

Quanzhou lamp is praised as the representative of the festive lantern in southern China, in the long history process, it plays the important function of cultural exchange and transmission. According to historical records, city was founded in Quanzhou since tang, and the custom of yuanxiao festival was quickly spread to Quanzhou because of the southward migration of the natives. During the period of the two song dynasties, the festival lantern in Quanzhou was the best in the world, especially in the southern song dynasty. Every year, the ancient city of Quanzhou lights up and shines brightly, attracting tens of thousands of Chinese and foreign tourists. As the cultural treasure of the historic city, Quanzhou lamp has won the general praise of the people from home and abroad with its unique aesthetic and artistic charm. This wonderful art is in the fertile soil of the historical and cultural city.

\section{The Art Form of Quanzhou Festival Lamp}

The Quanzhou lamp from simple to complex, from one variety to several varieties, has undergone over a thousand years of development. Quanzhou lamps combine sculpture, painting, modeling, color, calligraphy and bleaching. It is different from all the lamps in the country, with the unique engraved paper, the needle technique and the silk veneer, making the viewer reluctant to return. The artistic value of the festival lamp in Quanzhou is reflected in the form, the work, the meaning and so on.

\subsection{The Appearance Is Varied}

The festival lamp is a visual artwork and the appearance is visual impression. Quanzhou lamps include the person lamp, the palace lamp, the headless lamp, the embroidery lamp, trotting horse lamp, the pull lamp, the carved festival lamp and other kinds of styles. Floor lamp is placed on the ground or on a special shelf, which is large, magnificent, bright, and often equipped with lantern art. The hanging lamp can be hung under the carved beams or between the trees. It is relatively small in volume, but is exquisitely crafted, colorful and beautifully patterned. The material filament lamp and the needle lamp are the representatives of hanging lamps. Water lanterns are usually placed in the groove on the surface of the river or pond. Generally use waterproof material and highlight the brightness of the light and beautiful modeling, reflecting water shimmering and colorful. Carp lamps and lotus lanterns are common water lamps. The drawing lamp is the light that the child plays on the 
hand in the yuan snack. This kind of lamps are small and exquisite, most are made by the modeling of the 12 animal signs, such as jade rabbit lamp, small bird lamp, rooster lamp and so on. In addition, there are drag-led and waved lanterns, such as dragon lanterns.

Quanzhou festival lamp is simple and natural in modeling with harmonious proportion, its design follows the principle which integrates the content and form. Through the change of form's big or small, square or round, open or closed, and the change of line's curved or straight, fast or slow, long or short, it embodies the meaning of the work. In order to achieve the perfect combination of application and beauty, give a person the sense with harmony and stability.

\subsection{The Production Process Is Diversified}

After Quanzhou lanterns inherited the characteristic of Zhongyuan lanterns, it combined with the local culture, and innovated continuously on the basis of its development. The form is richer and many new forms of lanterns with local characteristics has been created. In terms of its technological characteristics, it can be divided into three categories: the material filament lamp, the boneless lamp and the bamboo lamp.

\subsubsection{Material Filament Lamp}

The material filament lamp's main raw materials are the cardboard and viscose, the main tools are the engraving and gasket. First, the producer designs the modeling of the lamp, breaks down the lamp into the paper plate accurately according to its shape, and draws various patterns designed in advance on the paper plate, and then puts it on a mat, with knives carving. The blade is exquisite, and the lines are fine, like hair. Finally, the carved cardboard is glued to the shape with silk ear. Along with the development of the craft, The material filament lamp is better. The lamp has no skeleton and is carefully stitched together with carved cardboard. It contains the principles of physical mechanics.

\subsubsection{Boneless Lamp}

In the late 1970s, the boneless lamp is created by a festival lantern artist named CAI Binghan in Quanzhou. He combined with the northern traditional lantern craft. The pattern of this lamp is all made of steel needles on the drafting paper. The size of each hole in the lamp should be uniform. The light source is released from the needle, appearing glittering, translucent and dazzling. There is a certain similarity in the making technique between material filament lamp and boneless lamp. The design of the lamp is geometric arithmetic, usually the design and conception account for about two-thirds of the time spent on a lamp. As long as half a centimeter of deviation can cause the change of the whole lamp.

\subsubsection{Bamboo Lamp}

The bamboo lamp is Quanzhou's traditional festival lamp form. When making bamboo lamp, use paper to bind bamboo into the skeleton of a lamp at first, then stick the sheets of paper or silken cloth onto the skeleton, describe pattern, hang up the silk ear and lace, then the bamboo lamp is done. In contrast, the production process of bamboo lamp is relatively simple. It retains the traditional manufacturing process of the central plains' lanterns, which are the main varieties of lanterns in many parts of our country. In Quanzhou, the process of bamboo lamp concentrates in the paper industry, and the making process of the lamp increases with the improvement of the paper paste technology, which gradually appears the situation in the present.

\subsection{The Artistic Conception Is Profound and Beautiful}

Giving people bright, warm and joyous, lanterns are also given a profound meaning, it is regarded as to eliminate the evil spirits, bless the auspicious things of good health. And because of the multiple good faith, lanterns will be more popular with people. Traditional lanterns are used by bamboo sticks as a bone, pasted with color paper, painted with flowers, birds, figures and landscape pattern. Then write the words of the auspicious blessings, decal edge with silk ear and built in candles. It was the main form of festival lamps in the early parts of the country. A light lantern is a story. In order to express people's thoughts, desires and good yearning, the patterns on the lantern are the stories and legends of the local culture, the flowers and birds, the poems and so on.

Quanzhou festival lamp is a form of expression of folk custom. Baba light(see fig.1) is a special folk lantern in Yingxi river. It came from the ancient towing a boat, it had been in the southern song dynasty for more than 500 years. Baba light is fasten with rope. Each of the leaders was tied up with 
a pole and a large rope in his chest. They made their boats and twisted their bows, pulled the lamp array marching forward, like pulling a boat. So the name of Baba light comes from this.

\section{The Continuity and Development of the Quanzhou' Festival Lamp in the Background of the Sea Silk Culture}

Quanzhou lamp with distinct features of traditional manual skills and social customs, is an important intangible cultural heritage. As a living culture, the lantern festival is more valuable to us. Now some excellent folk art disappear gradually in the development of modern society, especially with the change of the modern way of life, the folk art around us is dying every year, even for the sake of throwing away and destroying. There is no reason why we should not protect our ancestral culture from our ancestors, as we do to protect the ecological balance. In order to protect and carry forward this important cultural heritage of Quanzhou festival lamp, we need to continue to make cultural products, gradually form the region culture characteristic of Quanzhou to create a new urban culture brand. For the sake of protecting and developing Quanzhou festival lamp art better, it is necessary to keep pace with the times and discuss the new way of the festival lamp in Quanzhou.

\subsection{In the Process of Making Materials}

Traditional paper lantern has a short life span, it is vulnerable to the destruction of the natural and human environment, and it is not suitable for landscape layout. However, the combination of new environmental decoration materials and modern technology can solve the problem. In recent years, some lamps have been used in sound, light and electricity. A series of energy-saving lanterns, like energy-saving lamps, can improve urban taste and environmental protection.

\subsection{The Quanzhou Lamps Are Applied to the Modern Environment}

The Quanzhou festival lamp wants to develop and expand, it should keep up with the times and integrate into modern life. For example, make Quanzhou lamp as a notable characteristic of Quanzhou. Introduce Quanzhou lamp into urban construction, like street landscape construction(see fig.2); Introduce Quanzhou lamp into cultural construction, for example, lantern handicrafts go into campus; And bring the Quanzhou lanterns into the home decor. The fusion of festival lamp and household can make the festival lamp go into the ordinary home. It reflects modern Quanzhou people's love of traditional process, increases the purchasing power of the Quanzhou lamps, lets more and more people study festival lamp, and can also lead the new trend of home decoration in southern Fujian at the same time.
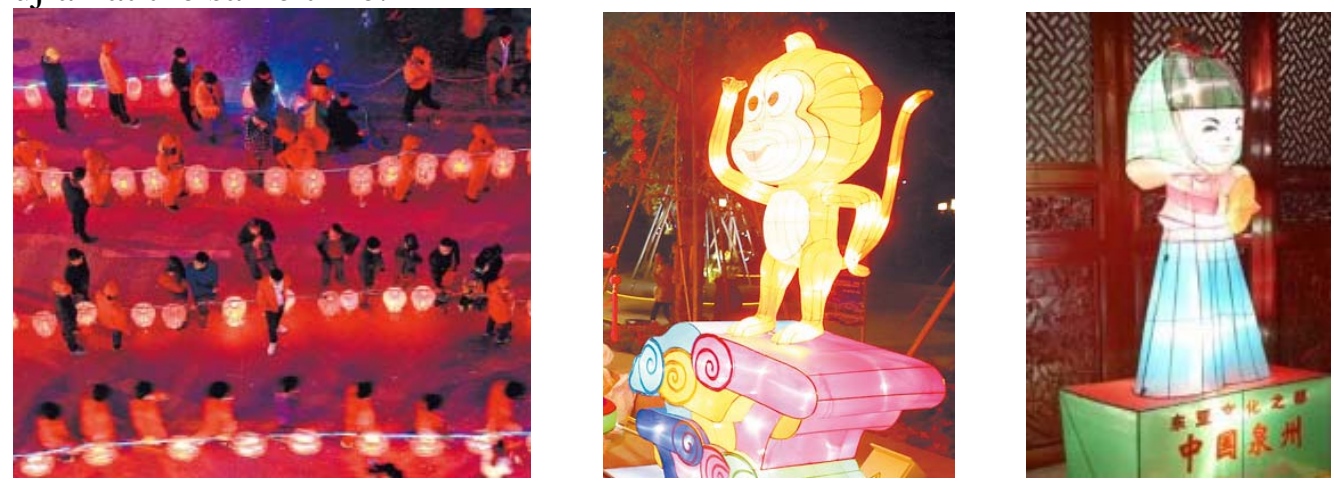

Fig.1 Baba lamp

Fig.2 Street view lamp Fig.3 The lamp of Huian woman image

As a typical of Quanzhou national culture and artistic image, Quanzhou Lantern Festival has added luster to the history and culture of Quanzhou, and has made the life of Quanzhou people more colorful. On the basis of inheriting the art of festival lamp art, the festival lamp craft art master is innovative and adventurous. Apply the art of the lantern art to the public art of the people's square in the East China Sea, continue to create the fine art of festival lamp, so as to gradually form the regional cultural characteristics of Quanzhou, creating a new urban culture brand. The emphasis is on integrating artistic elements of local characteristics, bringing the art to life and the masses. 


\subsection{Embody The Spirit Of Multivariate Times And Explore Innovation Actively}

The Li's glass-silk lantern, developed by Li Yaobao, is an outstanding representative of Quanzhou festival lamp art, provides a very good ideas and examples for our thinking in the development of folk art inheritance and innovation. Glass-silk lamp applies the silk art to the festival lamp flawlessly. The characteristics of the non-skeleton support of the filament lamp bulb with the filament lamp are retained. This paper applies the principle of standing bar and roof beam in the ancient buildings in southern Fujian. It concentrates the decorative patterns and mechanical patterns of ancient buildings in southern Fujian region. Under the premise of reasonable inheritance, it has bold innovation and development. Its inheritance of traditional art is not singular, but a combination of absorbing and blending. The silk art was introduced into the city of Danyang in Jiangsu province and then spread to the capital, and then flowed into Quanzhou, through continuous discovery and innovation, formed today's glass-silk lamp. Scientifically pass on and protect the historical cultural and regional culture of Quanzhou, it embodies the spirit and organic integration of the multicultural, truly achieves the innovation, creativity and creation of Quanzhou lamps under the background of Hester culture.

\subsection{Develop in the Direction of Art Collection}

First, make the festival lamps as an important project of cultural exchanges, collect the design of the festival lamp craft to establish the archive index. Considering the large variety of lamps, set up different showrooms to show that Quanzhou lamps' unique charm, and further enhance the reputation of Quanzhou lamps. Secondly, the government should encourage fans to collect the lamps as a collection of personal collectibles. This also opens up new market opportunities while protecting the technology of the lamps and improving the appreciation of collectors. Besides, for the younger generation who are interested in inheriting the lamp process, the education is a great way to cultivate their innovative and sustainable development consciousness.

\subsection{Explore the History and Culture and Raise Public Awareness}

Quanzhou has a long history, cultural prosperity and numerous historical sites. It has the reputation of East Asian Cultural Capital, Seashore Zoulu, the Beginning of Ancient Maritime Silk Road and World Religious Museum. Quanzhou festival lamp, which grows in the people of Quanzhou, develops traditional folk custom. Its millennium development, demise, rise, creative survival and artistic journey also fully embody the unique folk culture of Quanzhou. Like all traditional handicrafts, the Quanzhou festival lamp is made without posterity. Although the leaders of Quanzhou are very concerned, there are few people who can pass on this ancient craft. Therefore, not only the higher authorities should provide material support, but the vast art workers should act actively. As shown in fig.3, take the image of Huian women in Quanzhou, and make a lamp with representative characters in Quanzhou to expand the use of the lamps. Combining with the creative industries of modern society, combining with new materials and new technologies, we will develop innovative Quanzhou lamps of the time breath.

\section{Summary}

Quanzhou festival lamp sets a variety of art forms, it is an important intangible cultural heritage and it contains rich cultural value and artistic value. Quanzhou festival lamp is the material carrier that reflects traditional culture. It is elegant in modeling, craft and artistic conception. Today, Quanzhou festival lamps are affected by the multicultural and technology. We need to rediscover the art of the sea silk culture, further protect and develop the Quanzhou lamp art to truly realize the innovation, originality and creation of Quanzhou festival lamp in the context of sea-silk culture.

\section{References}

[1]. Huang Jian. Quanzhou lantern art research [M]. Haichao photography art press. 2009.1.

[2]. Gan Jinxiu.The present situation and development of Quanzhou festival lamp [J].Art theory.2009.11. 
[3]. .Huang Yan. The intangible cultural heritage in the silk road of the sea -- the research of the cultural and contemporary heritage of guangcai [J]. Cultural heritage.2015, (05): 145—1 50.

[4]. Yu Guanghai. Traditional regression and protection [M]. Shandong university press. 2005: 165.

[5]. Wei Jun.The history and development of the festival lamp in Quanzhou [J].Fujian art.2009.6. 